\title{
Regulatory Volume Decrease in Neural Precursor Cells: Taurine Efflux and Gene Microarray Analysis
}

\author{
Reyna Hernández-Benítez Adriana Sedeño-Cortés Gerardo Ramos-Mandujano \\ Herminia Pasantes-Morales
}

División de Neurociencias, Instituto de Fisiología Celular, Universidad Nacional Autónoma de México, México DF, México

\section{Key Words}

Stem and progenitor cells • Taurine $\cdot$ Swelling $•$ Gene expression analysis

\begin{abstract}
Background/Aims: Neural stem/ progenitor cells (NPCs) endure important changes in cell volume during growth, proliferation and migration. As a first approach to know about NPC response to cell volume changes, the Regulatory Volume Decrease (RVD) subsequent to hypotonic swelling was investigated. Methods: NPCs obtained from the mesencephalon and the subventricular zone of embryonic and adult mice, respectively, were grown and cultured as neurospheres. Cell volume changes were measured by large-angle light-scattering and taurine efflux by $\left[{ }^{3} \mathrm{H}\right]$-taurine. Expression of genes encoding molecules related to RVD was analysed using a DNA microarray obtained from NPC samples. Results: Embryonic and adult NPCs exposed to osmolarity reduction $(\mathrm{H} 15, \mathrm{H} 30, \mathrm{H} 40)$ exhibited rapid swelling followed by RVD. The magnitude, efficiency and pharmacological profile, of RVD and of $\left[{ }^{3} \mathrm{H}\right]$-taurine osmosensitive efflux were comparable to those found in cultured brain cells, astrocytes and neurons. The relative expression of genes encoding molecules related to volume regulation, i.e. $\mathrm{K}^{+}$and $\mathrm{Cl}^{-}$channels, cotransporters, exchangers and aquaporins were identified in NPCs. Conclusion: NPCs show the ability to respond to hypotonic-evoked volume changes by adaptative recovery processes, similar to those found in other cultured brain cells. Genes related to molecules involved in RVD were found expressed in NPCs.
\end{abstract}




\section{Introduction}

Cell volume regulation is exhibited by most animal cells as a protective response facing osmotic stress. When intracellular solute content or extracellular osmolality is altered, a rapid transmembrane flow of water occurs to restore the osmotic equilibrium, leading to cell swelling or shrinkage $[1,2]$. This change in cell volume is rapidly normalized by the efflux of osmolytes after swelling by the regulatory volume decrease (RVD), or by the active accumulation of osmolytes after shrinkage by the regulatory volume increase (RVI). These are complex processes involving volume sensors and transduction signalling chains which ultimately result in activation of the transport pathways, which move osmolytes in the direction required to regulate water fluxes towards normalization of the cell volume. Osmolytes are inorganic and organic osmotically active solutes present in high concentrations in the cytosol, and able to traslocate across the membrane when cells are exposed to hypotonic or hypertonic stress. The inorganic osmolytes are intracellular ions such as $\mathrm{Na}^{+}, \mathrm{K}^{+}$and $\mathrm{Cl}^{-}$. Organic osmolytes comprise an heterogeneous group of small molecules including amino acids (alanine, glutamate, glycine, and taurine), polyols (sorbitol, myoinositol), and methylamines (creatine, glycerophosphorylcholine, N-acetyl-aspartate, and phosphoethanolamine) $[3,4]$.

Osmotic stress is particularly important in brain because of the restriction imposed by the rigid skull. When brain undergoes tissue expansion (swelling), the cranial constriction leads to the rupture of vasculature, generating ischemic episodes, neuronal death and functional deficits. Facing acute hypotonic stress, osmolyte efflux allows the volume recovery of neural cells back to normal, throughout activation of the RVD process. Inorganic osmolytes $\mathrm{K}^{+}$and $\mathrm{Cl}^{-}$are main contributors to RVD due to their high intracellular concentrations. Organic osmolytes also participate in the volume regulatory process. Among the amino acids playing a role as osmolytes, taurine is a major osmoregulator, being preferentially lost during cell swelling [5]. Other amino acids, glutamate, aspartate, GABA and alanine, are also released from brain cells upon swelling $[3,4,6]$.

Osmolytes traslocate via the activation of a variety of transport mechanisms, including electroneutral cotrasporters and exchangers, $\mathrm{K}^{+}$channels, $\mathrm{Cl}^{-}$channels, and an anion channel presumably permeable to $\mathrm{Cl}^{-}$and small organic compounds like taurine, named volumesensitive anion channel or volume-regulated anion channel (VRAC) $[4,7,8]$. This channel is blocked by NPPB, DIDS, A9C, niflumic acid, tamoxifen, and by DCPIB, the most selective inhibitor so far described [9]. This volume-sensitive channel would be the main pathway for the volume-activated organic osmolyte translocation during RVD, including the efflux of taurine

RVD has been extensively studied in mature cell types of the brain, in vivo and in vitro, but there is no information available about the cell volume regulation in neural precursor cells (NPCs). NPCs are a group of cells that comprises both stem and progenitor cells. NPCs are abundant in the developing brain, and restricted to specific areas in the adult brain, where they are capable to initiate neurogenesis [10]. NPCs exhibit three main features: (i) sustained proliferation, (ii) the ability of self-renewal, and (iii) the multipotency or capacity to differentiate into all the cell lineages of the nervous system [11]. NPCs can be isolated from brain tissue and cultured in vitro, when their proliferation is sustained by growth factors such as EGF and/or bFGF. Cells grow in this culture as floating spherical structures named neurospheres [12]. The physiology of NPCs has been extensively studied, but so far their ability to regulate cell volume has not been explored. This is of relevance considering that changes in cell volume are key players in salient features of the NPC physiology such as proliferation and migration. The present study was designed to identify and characterize RVD in embryonic and adult NPCs exposed to hypotonic stress as well as the osmodependent release of taurine. The relative expression of genes in NPCs encoding molecules related to RVD was investigated using the DNA microarray analysis performed by Ramos-Mandujano et al. [13]. 


\section{Materials and Methods}

\section{Materials}

DMEM/F12, glutamax 100×, human insulin, human transferrin, human epidermal growth factor (EGF), human basic fibroblast growth factor (bFGF), penicillin/streptomycin, and trypsin-EDTA solution $(0.05 \%)$ were from Invitrogen, Life technologies. Progesterone, sodium selenite, putrescine (1,4-diaminobutanedihydrochloride), poly-L-lysine hydrobromide, o-phthaldialdehyde, SITS, DIDS, and NPPB were from Sigma-Aldrich. $\left[{ }^{3} \mathrm{H}\right]$-taurine and DCPIB were from American Radiolabeled Chemicals and from Tocris respectively. All salts for preparation of osmotic solutions were from J.T. Baker.

\section{Cell culture}

Neural precursor cells were obtained from the embryonic mouse mesencephalon or from the subventricular zone of lateral ventricles of adult mouse brain. All animals used in this study were cared according the Norma Oficial Mexicana NOM-062-ZOO-1999. Separately, tissue from each region was dissociated into a cell suspension. Cells were grown in DMEM-F12 medium supplemented with 1\% glutamax 100×, $25 \mu \mathrm{g} / \mathrm{mL}$ insulin, $100 \mu \mathrm{g} / \mathrm{mL}$ transferrin, $20 \mathrm{nM}$ progesterone, $60 \mu \mathrm{M}$ putresine, $30 \mathrm{nM}$ sodium selenite, penicillin/streptomycin (50 U/mL and $50 \mu \mathrm{g} / \mathrm{mL}$ ), and EGF and bFGF (20 ng/mL each). The culture was maintained at $37^{\circ} \mathrm{C}$ in $5 \% \mathrm{CO}_{2}$ during 5-9 days to obtain neurospheres. Then, neurospheres obtained were disaggregated using trypsin-EDTA solution (0.05\%) to obtain a single NPC suspension. For release experiments, NPCs were plated onto 12 -well plates pre-treated with poly-L-lysine $(0.01 \%)$ at a density of $1 \times 10^{6}$ cells/well. For cell volume measurements, cells were plated onto pre-treated poly-Llysine coverslips $(8 \times 36 \mathrm{~mm})$ at density of $2 \times 10^{5}$ cells/coverslip. After plating the cells were incubated in culture medium for 2 hours before experiments.

HPLC

NPC samples were collected and washed with PBS, resuspended in $150 \mu \mathrm{L}$ of PBS and sonicated (30 s) with a Branson Sonifier-250. Aliquots of $10 \mu \mathrm{L}$ of each sample were mixed with $400 \mu \mathrm{L}$ ethanol (20 $\mathrm{min}$ ), then centrifugated and filtered (sterile membrane of $0.22 \mu \mathrm{m}$ ). Aliquots of $10 \mu \mathrm{L}$ of the filtered were derivatized 1:1 with o-phthaldialdehyde and injected into a Beckman liquid chromatograph system. An ODS column $(4.6 \times 250 \mathrm{~mm}$ internal diameter $)$ was used. The column effluent was monitored with a fluorescence detector (emission at $460 \mathrm{~nm}$ and excitation at $330 \mathrm{~nm}$ ). The mobile phase was methanol/potassium acetate $(0.1 \mathrm{M}, \mathrm{pH} 5.5)$ and was run at a rate of $1.5 \mathrm{~mL} / \mathrm{min}$ in a linear gradient (15 min). The retention time in the chromatogram in the standard solution was in this order: aspartate, glutamate, glutamine, glycine, taurine, alanine, and GABA. The cell content of amino acids was determined according to the corresponding standard solution and normalized per milligram of cell protein.

\section{Release experiments}

The isotonic standard solution used for release experiments and cell volume recordings contained (in mM): $135 \mathrm{NaCl}, 4.7 \mathrm{KCl}, 1.7 \mathrm{KH} 2 \mathrm{PO} 4,1 \mathrm{CaCl} 2,1.17 \mathrm{MgSO} 4,10 \mathrm{HEPES}, 5$ glucose (pH 7.4, $300 \mathrm{mOsm}$ ). Hypotonic solutions were prepared by equiosmolar $\mathrm{NaCl}$ reductions. Osmolarity was verified by a freezing point osmometer from Precision Systems Inc. (Natick, MA, USA). Chloride channel blockers were dissolved into the isotonic or hypotonic solutions at the concentrations indicated in Figs, and were present throughout the experiment. For release experiments, NPCs were preloaded for $1 \mathrm{~h}$ at $37^{\circ} \mathrm{C}$ with $\left[{ }^{3} \mathrm{H}\right]$-taurine $(0.5 \mu \mathrm{Ci} /$ $\mathrm{mL}$ ). At the end of the incubation, the loading medium was discarded, and cells were washed with [ $\left.{ }^{3} \mathrm{H}\right]-$ taurine-free medium. Isosmotic medium $(1 \mathrm{~mL})$ was added, collected and replaced every minute during 5 min to attain the basal release. Thereafter, perfusion continued with hypotonic medium during $10 \mathrm{~min}$. At the end of the experiment, NPCs were lysed and collected. The radioactivity present in the efflux samples and in the cell lysates were determined by liquid scintillation. Total incorporated taurine was obtained by adding the radioactivity in the efflux samples to that remaining in the cell lysates. Results are expressed as radioactivity released per minute and calculated as percentage of the total incorporated during loading.

\section{Volume measurements}

The relative cell volume was estimated by the large-angle light-scattering system [14] as the volume changes under experimental conditions, relative to volume in isotonic conditions. NPCs plated on rectangular 
Table 1. Concentration of osmolyte amino acids in cultured NPCs and in their tissue of origin. Concentrations were determined by HPLC and expressed as $\mu$ moles/g protein. Results are mean \pm SEM $(n=3)$

\begin{tabular}{cccccc}
\hline $\begin{array}{c}\text { Amino } \\
\text { acid }\end{array}$ & $\begin{array}{c}\text { Embryonic } \\
\text { mesencephalon } \\
\text { (E13.5d) }\end{array}$ & $\begin{array}{c}\text { NPCs from } \\
\text { embryonic tissue }\end{array}$ & $\begin{array}{c}\text { SVZ of lateral } \\
\text { ventricles of adult } \\
\text { brain }\end{array}$ & $\begin{array}{c}\text { NPCs from } \\
\text { adult tissue } \\
\text { Control }\end{array}$ & $\begin{array}{c}\text { NPCs from } \\
\text { adult tissue } \\
\text { +Taurine } 10 \\
\text { mM }\end{array}$ \\
\hline Glutamate & $120 \pm 15.1$ & $87.4 \pm 12.5$ & $15.5 \pm 2.8$ & $15.5 \pm 1.6$ & $11.7 \pm 2.4$ \\
Glutamine & $94.6 \pm 12.5$ & $80.5 \pm 8.7$ & $7.8 \pm 2.3$ & $60 \pm 7.6$ & $20.6 \pm 1.3$ \\
Glycine & $99.5 \pm 16$ & $122.2 \pm 16.5$ & $13.5 \pm 2.3$ & $83.7 \pm 11.2$ & $54.6 . \pm 8.4$ \\
Taurine & $356.8 \pm 14$ & $38 \pm 5$ & $31.7 \pm 5.7$ & $8.9 \pm 1.7$ & $210.6 \pm 21.3$ \\
Alanine & $227.3 \pm 19.1$ & $127.5 \pm 20$ & $7.7 \pm 1.2$ & $42.6 \pm 7$ & $26.5 \pm 2.1$ \\
\hline
\end{tabular}

coverglasses at $90 \%$ confluence, were placed at a $50^{\circ}$ angle relative to the excitation light on a cuvette filled with isotonic medium ( $300 \mathrm{mOsm}$ ) in an Fluoromax-3 Horiba luminescence spectrometer. Cells were excited at $585 \mathrm{~nm}$ with an Argon-arc lamp and light scattering was detected at the same wavelength. Reductions in osmolarity were made by reduction of $\mathrm{NaCl}$ content in the isotonic medium. Relative cell volume changes were calculated as the proportion $\left[\mathrm{l}_{\mathrm{o}} / \mathrm{l}_{\mathrm{t}}\right]$, where $\mathrm{l}_{\mathrm{o}}=$ isotonic light scattering signal average in $100 \mathrm{~s} ; \mathrm{l}_{\mathrm{t}}=$ light scattering signal at time t.

\section{Gene expression analysis}

The data set used for this analysis was obtained from NCBI's Gene Expression Omnibus [15, 16] with reference GSE53547 (see supplementary files available at http://www.ncbi.nlm.nih.gov/geo/query/ acc.cgi?acc= GSE53547). For each sample, the columns used were those corresponding to "Raw intensity (mean)" and "Background (mean)". Only genes with an expression value (raw intensity value) higher than that of the background were considered. Genes in the columns "Symbol", "Name" or "Description", were those containing terms related to transporters, channels, pumps, carriers, exchangers and aquaporins. Heat maps were built using the 3-scale-color gradient tool of Excel Software. Each raw intensity value in the map associates red, black or green colour to low, medium or high gene expression respectively.

\section{Results}

Osmolyte amino acid content in NPCS

The concentration of amino acids acting as brain osmolytes in NPCs and in their tissue of origin was measured by HPLC. In tissue samples of embryonic brain, taurine was present in a markedly high concentration, $357 \mu \mathrm{mol} / \mathrm{g}$ protein, while in the tissue obtained from the subventricular zone (SVZ) of adult brain, its concentration was much lower, $32 \mu \mathrm{mol} / \mathrm{g}$ protein. This difference between the taurine content in embryonic and adult brain tissue is consistent with numerous reports from other brain areas. Not only taurine, but most amino acids were found at higher levels in the embryonic tissue (Table 1). The amino acid content of cultured NPCs derived from the embryonic brain was rather similar to that found in tissue, with the notable exception of taurine, which was essentially lost in NPCs, and of alanine which was about 40\% lower. In NPCs derived from the SVZ, glutamate content was the same as in the tissue, glycine and alanine increased markedly and taurine dramatically decreased (Table 1). Addition of $10 \mathrm{mM}$ taurine to NPCs derived from the SVZ substantially modified the concentration of osmolyte amino acids: whereas taurine increased markedly, the concentration of all other of amino acids decreased (Table 1). These results point to taurine as the preferred osmolyte in these cells.

\section{Hypotonicity-evoked [ $\left.{ }^{3} \mathrm{H}\right]$-taurine release in NPCs}

Taurine has been used as a representative of osmolyte amino acids due to its relative metabolic inertia and its presence largely free in the cytosol. In the present study, taurine efflux was followed by the labelled tracer $\left[{ }^{3} \mathrm{H}\right]$-taurine, as previously described [17]. The osmolarity of the NPC culture medium was maintained around $300 \mathrm{mOsm}$, an isotonic solution for these cells. NPCs from embryonic or adult mouse brain, when exposed to a hypotonic stimulus exhibited a typical $\left[{ }^{3} \mathrm{H}\right]$-taurine release response, consisting in an initial and immediate 
Fig. 1. Hypotonic release of taurine from NPCs. NPCs from embryonic or adult tissue were preloaded with $\left[{ }^{3} \mathrm{H}\right]$-taurine and superfused (1 $\mathrm{mL} / \mathrm{min}$ ) with isotonic medium (300 mOsm) during $5 \mathrm{~min}$, and then $10 \mathrm{~min}$ with hypotonic medium at $\mathrm{H} 15$ (255 mOsm), H30 (210 mOsm), H40 (180 mOsm) or H50 (150 mOsm). A. Time course of taurine release. Points represent the radioactivity released at each fraction, expressed as percentage of total

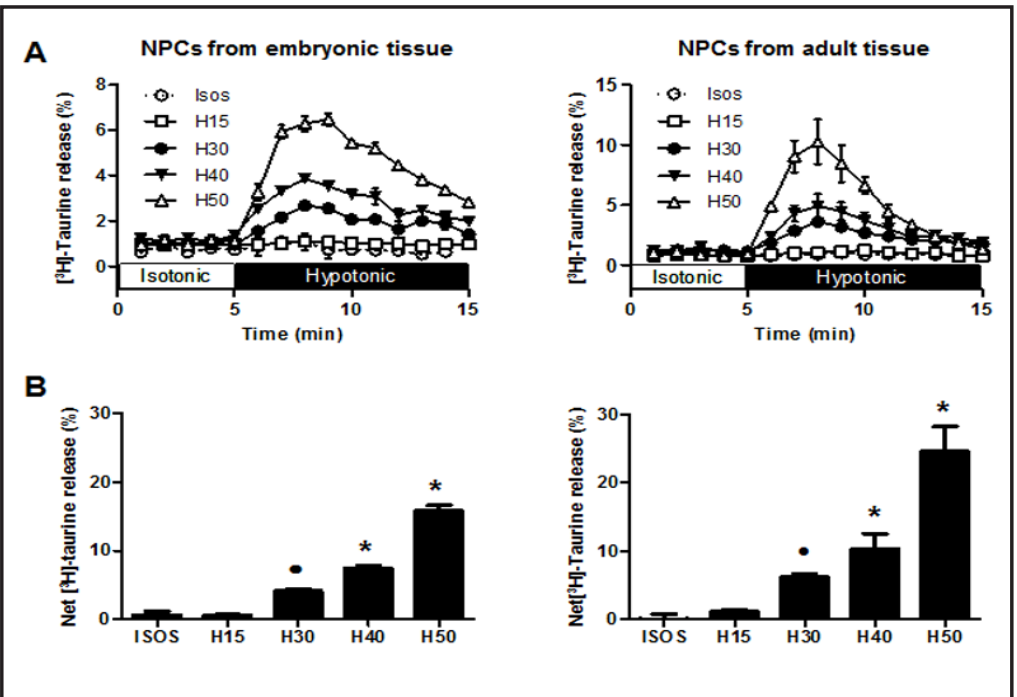
radioactivity accumulated during loading. B. Net taurine release. Net release was calculated as the sum of three main fractions of the peak minus the equivalent fractions of the isotonic release. Values are means \pm SEM of 7-8 experiments. Significant differences were determined by one-way ANOVA followed by a post-hoc Tukey test. Significantly different from isosmotic at $\bullet p<0.05$ or $* p<0.001$.

Fig. 2. Swelling and cell volume regulation in NPCs after hypotonic stimulus. Changes in cell volume were measured in NPCs from embryonic or adult tissue, exposed to H30, H40 or H50. A. Representative traces of changes in cell volume. B. Cell volume regulation. Bars indicate the cell volume recovery at the end of the experiment, expressed as percentage of maximal swelling. Values are means \pm SEM of 4-12 experiments.
A

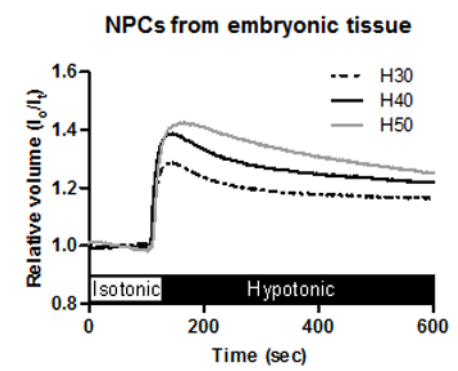

B

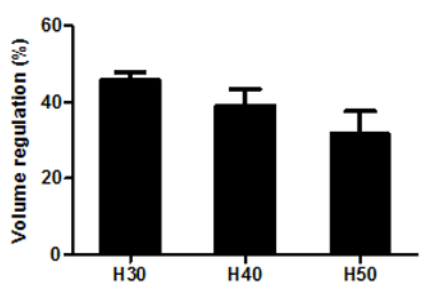

NPCs from adult tissue
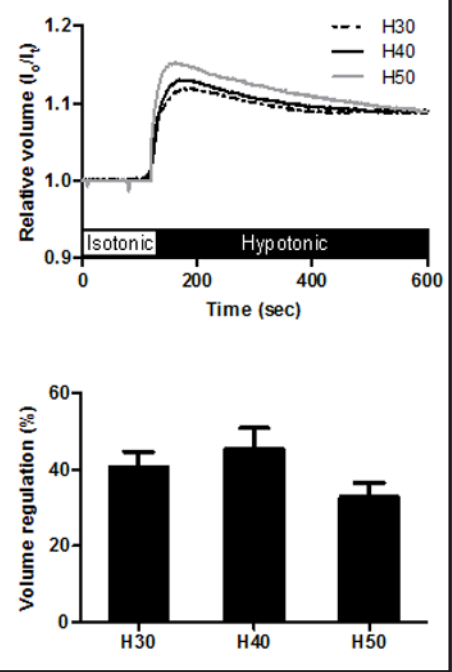

transient peak during the first 2-3 min after the stimulus, followed by a slower progressive decrease (Fig. 1A). The release was proportional to the reduction in osmolarity from 300 mOsm to 210 (H30\%), 180 (H40\%) and 150 (H50\%) mOsm. An osmolarity reduction of $15 \%$ did not stimulated the release of taurine (Fig. 1 A,B). The amount of taurine released at all osmolarities was higher in NPCs derived from the SVZ than from the embryonic tissue (Fig. 1B). The total net release of taurine during the 10 minutes of the experiment at $\mathrm{H} 30$ was $19 \%$ and $24 \%$ in NPCs from embryonic or adult brain, respectively (Fig. 1A)

\section{Regulatory volume decrease in NPCS}

Stimulation of NPCs with hypotonic medium (H30, H40, H50) induced the typical fast swelling and subsequent RVD. Cell swelling was proportional to the magnitude of the hypotonic medium and was maximal within 100-150 seconds after the stimulus. After maximal swelling, cells initiate the volume regulatory process (Fig. 2A). The efficiency of 
Fig. 3. Effect of anion channel inhibitors on $\left[{ }^{3} \mathrm{H}\right]$-taurine release and RVD in NPCs in H30. Cells were preincubated during 30 min previous to the hypotonic stimulus (H30) with SITS (100 $\mu \mathrm{M})$, DIDS $(100 \mu \mathrm{M})$, NPPB $(50 \mu \mathrm{M})$, or DCPIB $(10 \mu \mathrm{M})$. The blockers were present in media throughout the experiments, performed as described Fig. 1 and Fig. 2. A. Time course of taurine release. Points are means \pm SEM. B. Net taurine release. C. Maximal swelling. D.
B

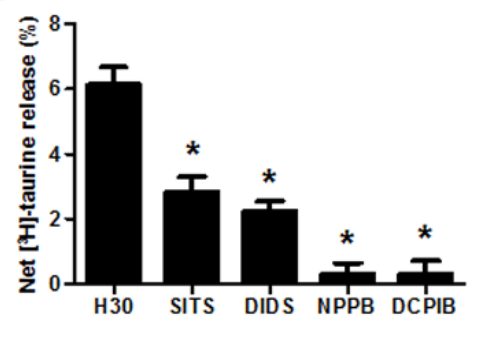

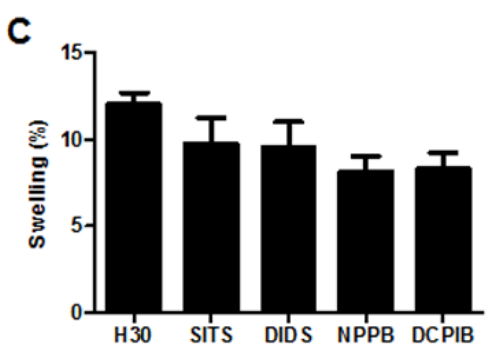

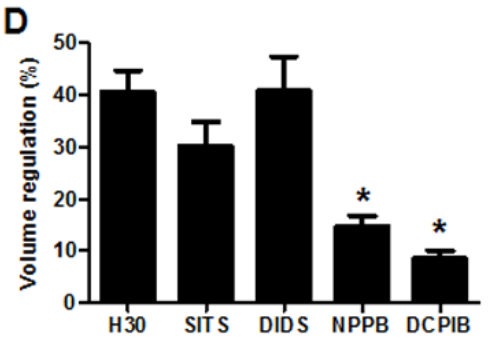

Volume regulation. Values are means \pm SEM of 4-9 experiments. Significant differences were determined by one-way ANOVA followed by a post-hoc Tukey test. Significantly different from hypotonic at * p $<0.001$.

RVD inversely proportional to the extent of swelling, being higher in $\mathrm{H} 30$ (46\%) and lower in $\mathrm{H} 50$ (32\%) (Fig. $2 \mathrm{~A}, \mathrm{~B})$. In NPCs from adult brain, RVD efficiency was similar in $\mathrm{H} 30$ and H40 (about 40-45\%) but lower in H50 (Fig. 2 A,B).

\section{Effects of anion channel inhibitors on hypotonic- induced $\left[{ }^{3} \mathrm{H}\right]$-taurine release and RVD in} NPCS

For the subsequent set of experiments only NPCs from adult brain were used. The effect of $\mathrm{Cl}^{-}$channel blockers (DCPIB, NPPB, SITS and DIDS) on taurine efflux evoked by $30 \%$ hypotonic medium is shown in Fig. 3. All blockers reduced the hypotonic efflux of $\left[{ }^{3} \mathrm{H}\right]-$ taurine (Fig. 3A). The potency of inhibition showed this order: DCPIB $>$ NPPB $>$ DIDS $>$ SITS. As shown in Fig. 3B the anion channel inhibitors NPPB and DCPIB reduced over $90 \%$ the hypotonic net $\left[{ }^{3} \mathrm{H}\right]$-taurine release, while the reduction by DIDS and SITS was $54 \%$ and $63 \%$, respectively. Only DCPIB decreased the isotonic release. None of the blockers modified significantly the H30 induced swelling (Fig. 3C). The effect of the blockers was examined on the RVD efficiency. NPPB and DCPIB markedly reduced volume regulation, 64 and $79 \%$ respectively whereas neither DIDS nor SITS affected RVD (Fig. 3D).

\section{Cell volume regulation-related genes in NPCs}

Gene expression of cell volume regulation-related molecules in NPCs was obtained from the data base GSE53547 at GEO [13]. This data base was built by using a library containing 23,232 gene-specific oligonucleotide probes for mouse. Genes for membrane traslocation molecules represent around 3\% of the total of Gene Bank identifiers in the original microarray (Fig. 4A).The relative expression in NPCs of putative genes encoding transport molecules (channels, transporters and pores), related to cell volume are presented in the heat map of the Fig. 4A. A sub-selection of putative gene families of molecules related to RVD were sorted out and presented in the Fig. 4B. A specific group of genes implicated in RVD is presented in Table 2. Data in Fig. 4 and in Table 2 show the relative expression according to heat maps built using the 3-scale-color gradient tool (Excel Software), which associates red, black or green colour to low, medium or high gene expression, respectively. Most genes 
Fig. 4. Gene expression in NPCs of molecules related to volume regulation. Relative expression of NPCs genes was obtained from GEO database (GSE53547). Genes in which description was associated with terms related to transport across the cell membrane were sorted, and their raw intensity values were heatmapped. Relative expressions are shown as a gradient with red for low, black for middle and green for high expression. A. Genes implicated in transmembranal transport in NPCs. B. Families of genes likely implicated in RVD.

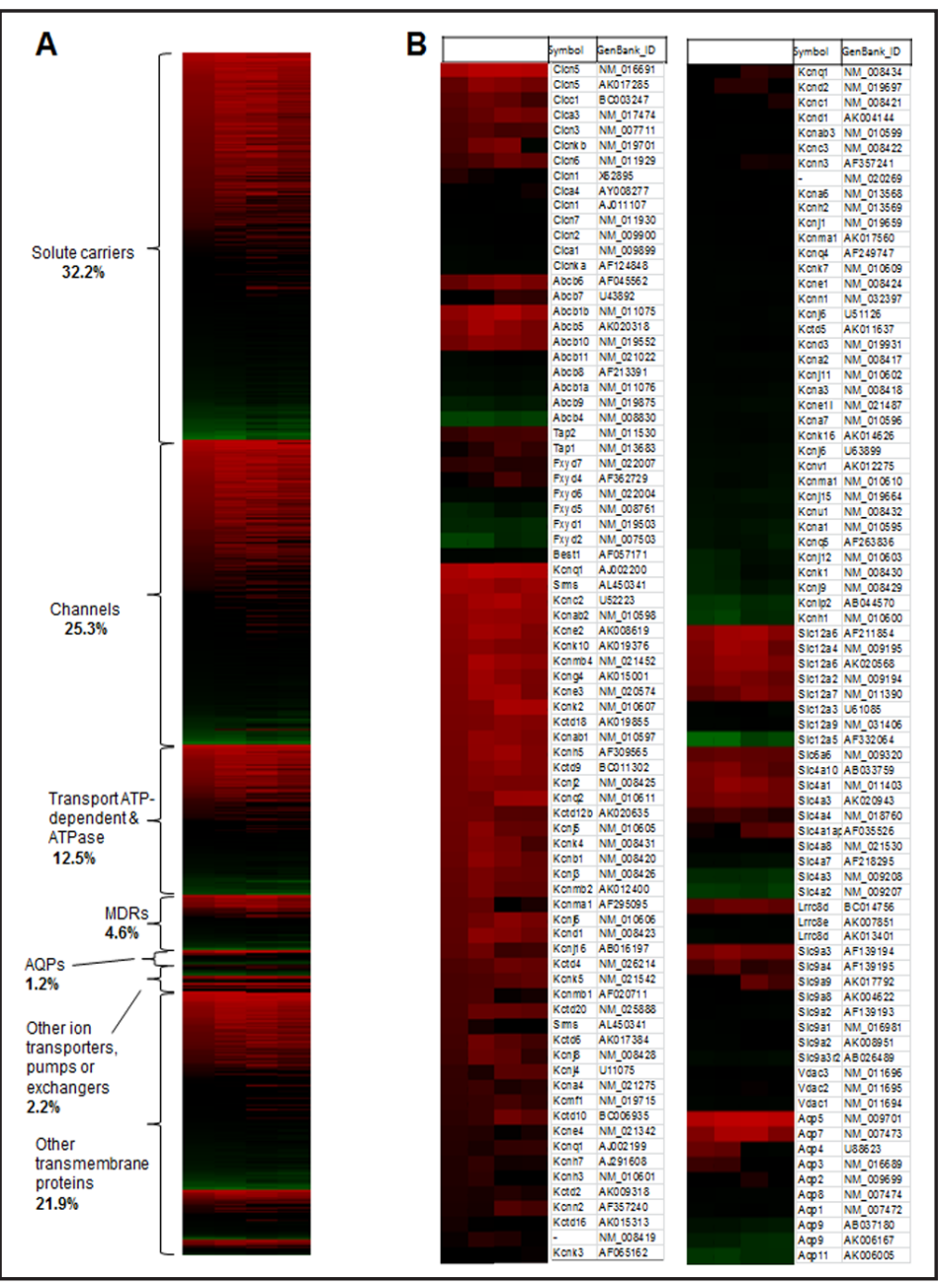

Table 2. Gene expression in NPCs of known molecules specifically related with RVD. Means of the relative expressions of each gene were obtained represented in the heat map. The Gene Bank identifier (ID), the common symbol, and the relative expression is presented, red, black and green correspond to low, middle and high expression, respectively

\begin{tabular}{|c|c|c|c|}
\hline \multicolumn{2}{|c|}{ Volume-Regulated Anion Channels } & \multicolumn{2}{|c|}{ Swelling-Activated $\mathrm{K}+$ channels } \\
\hline NM_007711 & Clcn3 & NM_010607 & TREKK1 \\
\hline NM_009900 & Clcn2 & NM_008431 & TRAAK1 \\
\hline NM_011076 & P-glycoprotein & NM_021542 & TASK2 \\
\hline NM_019503 & Phospholemman & NM_008418 & Kv1 \\
\hline AF057171 & Bestrophin & NM_019931 & Kv4 \\
\hline ВC014756 & LRRC8d & AF295095 & BK (Kcnma1) \\
\hline AK013401 & LRRC8d & AK017560 & BK (Kcnma1) \\
\hline AK007851 & LRRC8e & NM_010610 & BK (Kcnma1) \\
\hline NM_011694 & Vdac1 & AF020711 & BK (Kcnmb1) \\
\hline & KCl-cotransporters & AK012400 & $\mathrm{BK}(\mathrm{Kcnmb2})$ \\
\hline NM_009195 & KCC1 & NM_021452 & BK (Kcnmb4) \\
\hline AF332064 & KCC2 & NM_032397 & SK1 \\
\hline AK020568 & KCC3 & AF357240 & SK2 \\
\hline AF211854 & КСС3 & AF357241 & SK3 \\
\hline NM_011390 & KCC4 & AJ002200 & KCNQ1 \\
\hline \multicolumn{2}{|c|}{ Transient Receptor Potential Channels } & AJ002199 & KCNQ1 \\
\hline NM_011643 & TRPC1 & NM_008434 & KCNQ1 \\
\hline NM_009428 & TRPC5 & AF249747 & KCNQ4 \\
\hline NM_021450 & TRPM7 7 & AF263836 & KCNQ5 \\
\hline AF208026 & TRPV4 & \multicolumn{2}{|c|}{$\mathrm{Na} / \mathrm{H}$ Exchangers } \\
\hline & Aquaporins & NM_016981 & NHE1 \\
\hline NM_009699 & Аqр2 & AK008951 & NHE2 \\
\hline U88623 & Aqp4 & AF139193 & NHE2 \\
\hline NM_009701 & Aqp5 & AF139194 & NHE3 \\
\hline \multirow[t]{2}{*}{ NM_007474 } & Aqp8 & AB026489 & NHERF2 \\
\hline & & NM_011403 & Band3 \\
\hline
\end{tabular}

for anion channels showed medium/high expression. Genes for the voltage-activated and $\mathrm{Ca}^{2+}$-activated $\mathrm{K}^{+}$channels showed low/medium expression. Low expression was found for TREK/TASK channels as well as for TRP channels excepted for TRPc1 gene which showed 
a higher expression. From the electroneutral cotransporters the KCC2 and KCC4 genes showed medium/high expression. Genes encoding some isoforms of NHE showed medium expression whereas those for the anion exchanger Band 3 showed low expression (Table 2).

\section{Discussion}

The present study showed the occurrence of RVD in NPCs obtained from the SVZ of mice adult brain. RVD efficiency in NPCs was found comparable in magnitude to that observed in similar experiments in cultured astrocytes and neurons [18-20]. Results also showed that RVD in NPCs is accomplished through the basic mechanisms found in other brain cells. The prominent role of taurine and of the volume-regulated anion channel (VRAC) is emphasized. There is a still pending debate on whether VRAC serves as a pathway for both, $\mathrm{Cl}$ and organic osmolytes. In the origin of this discussion is first, that the energy-dependent transporters are not involved in the osmosensitive efflux of osmolyte amino acids or polyalcohols, and more significant, that this release is highly sensitive to $\mathrm{Cl}^{-}$channel blockers, including DCPIB, the agent considered as a specific VRAC blocker [9]. A number of $\mathrm{Cl}^{-}$channels and other molecules such as P-glycoprotein and phospholemman, have been proposed as the molecular entities of VRAC, but some features are clearly different from those of VRAC currents [7, 21, 22]. A recent study by Voss et al. [8], identifies a $\mathrm{Cl}^{-}$channel containing LRRC8 proteins as main constituents, which permeates taurine and operates for RVD. This may be a candidate to fit the molecular identity of VRAC.

The presence of volume regulatory mechanisms in NPCs obtained from the adult brain is of interest since besides relieving cell swelling, the control of cell volume is relevant to intrinsic features of the NPC physiology such as cell proliferation and migration, occurring throughout the life, in brain areas such as the olfactory bulb and the hippocampal dentate gyrus [23]. Furthermore, harmful events such as trauma, ischemia or epilepsy, increase proliferation and migration of NPCs from the SVZ in the adult brain, presumably as a repair mechanism for neurogenesis to functionally compensate for the damage [24]. Neurogenesis in the adult seems also implicated in more subtle changes of neuroplasticity. In the hippocampus, neurogenesis is reduced by adverse conditions such as chronic social stress [25], whereas it increases by physical activity or enriched environment [26]. These stimuli appear to improve the survival of proliferating NPCs [27]. Interestingly, a previous study from our laboratory has shown that NPCs in cultures containing taurine have markedly more cells than controls, because taurine is increasing the number of cultured NPCs in conditions to proliferate [13].

The key role played by changes in cell volume during proliferation and migration is well documented. During cell motility, local volume changes due to water flow across the membrane, driven by transporters, exchangers, channels and aquaporins, control the protrusion and retraction of lamellipodia at the front edge of migrating cells $[1,28]$. Changes in cell volume are now considered as part of the signals involved in the cycle progression during cell proliferation. Increasing cell volume is essential for allowing cells to attain the size necessary for the transition through the different phases of the cycle [29, 30]. This volume-proliferation interplay is critical in NPCs which endure continuous cycles of growth and proliferation.

Cell volume regulation is a complex process involving the operation of several channels, cotransporters and exchangers, represented by families of membrane proteins. In the present study, a DNA microarray analysis was conducted to identify in NPCs, the expression of genes encoding molecules implicated in RVD. These include $\mathrm{K}^{+}$channels, $\mathrm{Cl}^{-}$channels, $\mathrm{KCC}$ transporters, exchangers, aquaporins and TRP channels.

\section{$\mathrm{K}^{+}$and $\mathrm{Cl}^{-}$channels}

NPCs expressed at low/medium levels the genes encoding a number of families of $\mathrm{K}^{+}$channels. Several types of $\mathrm{K}^{+}$channels contribute to RVD by increasing $\mathrm{K}^{+}$efflux, thus 
contributing to reach the osmotic equilibrium. Most of them are not directly activated by swelling but by other signals concurrent with the change in cell volume. Among them are the $\mathrm{Ca}^{2+}$-activated large conductance $\mathrm{BK}$ or maxi $\mathrm{K}^{+}$channels, the intermediate/small conductance- $\mathrm{Ca}^{2+}$ activated $\mathrm{K}^{+}$channels, and the group of voltage-gated channels Kv and KCNQ channels. Genes for all these channels showed medium expression in the NPCs microarray. The two-pore domain $\mathrm{K}^{+}$channels TASK-2, TREK-1 and TRAAK1, also participate in RVD in various cell types [31]. Low expression of genes encoding these channels was found in NPCs. Genes encoding anion channels and other molecules known to traslocate $\mathrm{Cl}^{-}$were found expressed in the NPC microarray. ClC-2, ClC-3, P-glycoprotein and phospholemman (Fxyd1) are anion channels activated by hypotonic swelling [21,22] and some of them are implicated in RVD in brain cells [32]. Recently, bestrophins and LRRC8 have been functionally characterized and are postulated as essential components of the swelling-activated anion channel which presumably permeates $\mathrm{Cl}^{-}$and organic osmolytes (VRAC) [8]. This channel has been characterized in brain cells [33]. Genes for all these volume-sensitive anion channels showed medium/high expression in the NPC microarray.

\section{Cotransporters and exchangers}

Electroneutral cotransporters of the KCC family (KCC1-4), all are activated by cell swelling and contribute in part to RVD by mediating, together with channels, the volume corrective efflux of $\mathrm{K}^{+}$and $\mathrm{Cl}^{-}$[34]. KCC2 is specifically expressed in mature neurons, where participates in the regulation of cytosolic $\mathrm{Cl}^{-}$concentration and buffering of extracellular $\mathrm{K}^{+}$ [35]. High expression of genes encoding KCC2 was found in NPCs. $\mathrm{Na}^{+} / \mathrm{H}^{+}$exchangers (NHE) participate in RVI but its role in RVD is controversial. The anion exchanger AE1, or band 3 anion exchanger, has been implicated in the volume-sensitive taurine efflux [36], but genes encoding this molecule are not highly expressed in NPCs.

\section{TRP channels and aquaporins}

The family of mechanosensitive TRP channels respond to a variety of stimuli, including changes in cell volume. Those responsive to hypotonic swelling are members of the subfamilies TRPC1, TRPC5, TRPC6, TRPV4, TRM3 and TRPM7 (rev in Plant, 2014) [37]. While their activation by hypotonicity is firmly established, their role in cell volume regulation is less clear. TRPV4 is the subtype more likely implicated in RVD, via a functionally coupling to activation of $\mathrm{Ca}^{2+}$-dependent $\mathrm{K}$ channels. Such link has been found for TRPV4 in various cell types $[38,39]$ including astrocytes [40]. Aquaporins contribute to cytotoxic cell swelling in a variety of cells including brain cells. AQP4 is the channel present in astrocytes and is a crucial element in the pathological brain edema [41]. The role of AQP4 and other aquaporins in RVD is so far unclear. Genes encoding most TRP channels and aquaporins showed medium expression in NPCs.

\section{Abbreviations}

ABC (ATP binding cassette); Aqp (aquaporin); bFGF (basic fibroblast growth factor); BK (large-conductance $\mathrm{K}^{+}$channel); ClC (chloride channel); DCPIB (4-[(2-Butyl6,7dichloro-2-cyclopentyl-2,3-dihidro-10xo-1H-inden-5-yl)oxy] butanoic acid); DIDS (4,4'-diisothiocyanostilbene-2,2'-disulfonic acid); EGF (epidermal growth factor); $\mathrm{H}$ (hypotonic); GABA (gamma aminobutyric acid); GEO (Gene Expression Omnibus); HPLC (high-performance liquid chromatography); $\mathrm{KCC}\left(\mathrm{K}^{+} / \mathrm{Cl}^{-}\right.$Co-transporter); $\mathrm{NKCC}\left(\mathrm{N}^{+} / \mathrm{K}^{+} / \mathrm{Cl}^{-}\right.$ Co-transporter); NHE $\left(\mathrm{Na}^{+} / \mathrm{H}^{+}\right.$exchanger); NPCs (neural precursor cells; NPPB (5-nitro-2(3-phenylpropylamino)benzoic acid); RVD (regulatory volume decrease); RVI (regulatory volume increase); SVZ (subventricular zone); SK (small-conductance $\mathrm{K}^{+}$channel; SITS (4-acetamido-4'-isothiocyanatostilbene-2,2'-disulfonic acid); TRP (transient receptor potential). 


\section{Acknowledgements}

This work was supported by the grant PAPIIT-IN202313 from the Dirección General de Asuntos del Personal Académico (DGAPA).

\section{Disclosure Statement}

The authors declare that there are no conflicts of interest.

\section{References}

1 Lang F, Foller M, Lang K, Lang P, Ritter M, Vereninov A, Szabo I, Huber SM, Gulbins E: Cell volume regulatory ion channels in cell proliferation and cell death. Methods Enzymol 2007;428:209-225.

- Hoffmann EK, Pedersen SF: Cell volume homeostatic mechanisms: Effectors and signalling pathways. Acta Physiol (Oxf) 2011;202:465-485.

- Verbalis JG, Gullans SR: Hyponatremia causes large sustained reductions in brain content of multiple organic osmolytes in rats. Brain Res 1991;567:274-282.

-4 Pasantes-Morales H, Lezama RA, Ramos-Mandujano G, Tuz KL: Mechanisms of cell volume regulation in hypo-osmolality. Am J Med 2006;119:S4-11.

5 Tuz K, Ordaz B, Vaca L, Quesada O, Pasantes-Morales H: Isovolumetric regulation mechanisms in cultured cerebellar granule neurons. J Neurochem 2001;79:143-151.

-6 Rutledge EM, Aschner M, Kimelberg HK: Pharmacological characterization of swelling-induced d-[3h] aspartate release from primary astrocyte cultures. Am J Physiol 1998;274:C1511-1520.

7 Okada Y, Sato K, Numata T: Pathophysiology and puzzles of the volume-sensitive outwardly rectifying anion channel. J Physiol 2009;587:2141-2149.

-8 Voss FK, Ullrich F, Munch J, Lazarow K, Lutter D, Mah N, Andrade-Navarro MA, von Kries JP, Stauber T, Jentsch TJ: Identification of lrrc8 heteromers as an essential component of the volume-regulated anion channel vrac. Science 2014;344:634-638.

-9 Decher N, Lang HJ, Nilius B, Bruggemann A, Busch AE, Steinmeyer K: Dcpib is a novel selective blocker of $\mathrm{i}(\mathrm{cl}, \mathrm{swell})$ and prevents swelling-induced shortening of guinea-pig atrial action potential duration. $\mathrm{Br} \mathrm{J}$ Pharmacol 2001;134:1467-1479.

10 Gage FH, Temple S: Neural stem cells: Generating and regenerating the brain. Neuron 2013;80:588-601.

11 Ahmed S: The culture of neural stem cells. J Cell Biochem 2009;106:1-6.

12 Reynolds BA, Weiss S: Generation of neurons and astrocytes from isolated cells of the adult mammalian central nervous system. Science 1992;255:1707-1710.

13 Ramos-Mandujano G, Hernandez-Benitez R, Pasantes-Morales H: Multiple mechanisms mediate the taurine-induced proliferation of neural stem/progenitor cells from the subventricular zone of the adult mouse. Stem Cell Res 2014;12:690-702.

14 McManus M, Fischbarg J, Sun A, Hebert S, Strange K: Laser light-scattering system for studying cell volume regulation and membrane transport processes. Am J Physiol 1993;265:C562-570.

15 Edgar R, Domrachev M, Lash AE: Gene expression omnibus: Ncbi gene expression and hybridization array data repository. Nucleic Acids Res 2002;30:207-210.

-16 Barrett T, Wilhite SE, Ledoux P, Evangelista C, Kim IF, Tomashevsky M, Marshall KA, Phillippy KH, Sherman PM, Holko M, Yefanov A, Lee H, Zhang N, Robertson CL, Serova N, Davis S, Soboleva A: Ncbi geo: Archive for functional genomics data sets--update. Nucleic Acids Res 2013;41:D991-995.

17 Vazquez-Juarez E, Ramos-Mandujano G, Lezama RA, Cruz-Rangel S, Islas LD, Pasantes-Morales H: Thrombin increases hyposmotic taurine efflux and accelerates ici-swell and rvd in 3t3 fibroblasts by a src-dependent egfr transactivation. Pflugers Arch 2008;455:859-872. 
18 Pasantes-Morales H, Murray RA, Lilja L, Moran J: Regulatory volume decrease in cultured astrocytes. I. Potassium- and chloride-activated permeability. Am J Physiol 1994;266:C165-171.

19 Pasantes-Morales H, Murray RA, Sanchez-Olea R, Moran J: Regulatory volume decrease in cultured astrocytes. Ii. Permeability pathway to amino acids and polyols. Am J Physiol 1994;266:C172-178.

20 Moran J, Morales-Mulia S, Hernandez-Cruz A, Pasantes-Morales H: Regulatory volume decrease and associated osmolyte fluxes in cerebellar granule neurons are calcium independent. J Neurosci Res 1997;47:144-154.

21 Nilius B, Eggermont J, Voets T, Buyse G, Manolopoulos V, Droogmans G: Properties of volume-regulated anion channels in mammalian cells. Prog Biophys Mol Biol 1997;68:69-119.

$>22$ Okada Y: Cell volume-sensitive chloride channels: Phenotypic properties and molecular identity. Contrib Nephrol 2006;152:9-24.

23 Kornack DR, Rakic P: The generation, migration, and differentiation of olfactory neurons in the adult primate brain. Proc Natl Acad Sci U S A 2001;98:4752-4757.

24 Arvidsson A, Collin T, Kirik D, Kokaia Z, Lindvall O: Neuronal replacement from endogenous precursors in the adult brain after stroke. Nat Med 2002;8:963-970.

25 Gould E, Tanapat P, McEwen BS, Flugge G, Fuchs E: Proliferation of granule cell precursors in the dentate gyrus of adult monkeys is diminished by stress. Proc Natl Acad Sci U S A 1998;95:3168-3171.

26 Koehl M, Abrous DN: A new chapter in the field of memory: Adult hippocampal neurogenesis. Eur J Neurosci 2011;33:1101-1114.

27 Kempermann G, Wiskott L, Gage FH: Functional significance of adult neurogenesis. Curr Opin Neurobiol 2004;14:186-191.

-28 Jakab M, Ritter M: Cell volume regulatory ion transport in the regulation of cell migration. Contrib Nephrol 2006;152:161-180.

-29 Rouzaire-Dubois B, Malo M, Milandri JB, Dubois JM: Cell size-proliferation relationship in rat glioma cells. Glia 2004;45:249-257.

30 Habela CW, Sontheimer H: Cytoplasmic volume condensation is an integral part of mitosis. Cell Cycle 2007;6:1613-1620.

-31 Wehner F: Cell volume-regulated cation channels. Contrib Nephrol 2006;152:25-53.

-32 Moran J, Morales-Mulia M, Pasantes-Morales H: Reduction of phospholemman expression decreases osmosensitive taurine efflux in astrocytes. Biochim Biophys Acta 2001;1538:313-320.

-33 Akita T, Okada Y: Characteristics and roles of the volume-sensitive outwardly rectifying (vsor) anion channel in the central nervous system. Neuroscience 2014;275C:211-231.

34 Markadieu N, Delpire E: Physiology and pathophysiology of slc12a1/2 transporters. Pflugers Arch 2014;466:91-105.

35 Kahle KT, Deeb TZ, Puskarjov M, Silayeva L, Liang B, Kaila K, Moss SJ: Modulation of neuronal activity by phosphorylation of the k-cl cotransporter kcc2. Trends Neurosci 2013;36:726-737.

-36 Shennan DB: Swelling-induced taurine transport: Relationship with chloride channels, anion-exchangers and other swelling-activated transport pathways. Cell Physiol Biochem 2008;21:15-28.

-37 Plant TD: Trps in mechanosensing and volume regulation. Handb Exp Pharmacol 2014;223:743-766.

-38 Becker D, Blase C, Bereiter-Hahn J, Jendrach M: Trpv4 exhibits a functional role in cell-volume regulation. J Cell Sci 2005;118:2435-2440.

39 Hdud IM, Mobasheri A, Loughna PT: Effect of osmotic stress on the expression of trpv4 and bkca channels and possible interaction with erk1/2 and p38 in cultured equine chondrocytes. Am J Physiol Cell Physiol 2014;306:C1050-1057.

40 Benfenati V, Caprini M, Dovizio M, Mylonakou MN, Ferroni S, Ottersen OP, Amiry-Moghaddam M: An aquaporin-4/transient receptor potential vanilloid 4 (aqp4/trpv4) complex is essential for cell-volume control in astrocytes. Proc Natl Acad Sci U S A 2011;108:2563-2568.

41 Papadopoulos MC, Verkman AS: Aquaporin water channels in the nervous system. Nat Rev Neurosci 2013;14:265-277. 